\title{
Comprehensive two-dimensional gas chromatography-time-of-flight mass spectrometry for the forensic study of cadaveric volatile organic compounds released in soil by buried decaying pig carcasses
}

\author{
Catherine Brasseur ${ }^{\mathrm{a}}$, Jessica Dekeirsschieter ${ }^{\mathrm{b}}$, Eline M.J. Schotsmans ${ }^{\mathrm{c}}$, Sjaak de Koning ${ }^{\mathrm{d}}$, \\ Andrew S. Wilson ${ }^{\mathrm{c}}$, Eric Haubruge ${ }^{\mathrm{b}}$, Jean-Francois Focant ${ }^{\mathrm{a}, *}$ \\ ${ }^{a}$ CART, Organic and Biological Analytical Chemistry, Chemistry Department, University of Liège, Allée du 6 août, B6c, Sart-Tilman, B-4000 Liège, Belgium \\ b Department of Functional and Evolutionary Entomology, Gembloux Agro-Bio Tech, University of Liege, 2 Passage des Déportés, B-5030 Gembloux, Belgium \\ ${ }^{c}$ Forensic E Archaeological Sciences, School of Life Sciences, University of Bradford, West Yorkshire BD7 1DP, United Kingdom \\ d LECO Instruments GmbH, Marie-Bernays-ring 31, 41199 Mönchengladbach, Germany
}

\section{A R T I C L E I N F O}

\section{Article history:}

Available online $\mathrm{xxx}$

\section{Keywords:}

Comprehensive two-dimensional gas

chromatography $(\mathrm{GC} \times \mathrm{GC})$

Time-of-flight mass spectrometry (TOFMS)

Volatile organic compound (VOC)

Cadaver decomposition

Forensic

Geotaphonomy

Scripting

\begin{abstract}
A B S T R A C T
This article reports on the use of comprehensive two-dimensional gas chromatography-time-of-flight mass spectrometry (GC $\times$ GC-TOFMS) for forensic geotaphonomy application. Gravesoil samples were collected at various depths and analyzed for their volatile organic compound (VOC) profile. A data processing procedure was developed to highlight potential candidate marker molecules related to the decomposition process that could be isolated from the soil matrix. Some 20 specific compounds were specifically found in the soil sample taken below the carcass and 34 other compounds were found at all depths of the gravesoil samples. The group of the 20 compounds consisted of ketones, nitriles, sulfurs, heterocyclic compounds, and benzene derivatives like aldehydes, alcohols, ketones, ethers and nitriles. The group of the 34 compounds consisted of methyl-branched alkane isomers including methyl-, dimethyl-, trimethyl-, tetramethyl-, and heptamethyl-isomers ranging from $C_{12}$ to $C_{16}$. A trend in the relative presence of these alkanes over the various layers of soils was observed, with an increase in the amount of the specific alkanes when coming from the carcass to the surface. Based on the specific presence of these methyl-branched alkanes in gravesoils, we created a processing method that applies a specific script to search raw data for characteristic mass spectral features related to recognizable mass fragmentation pattern. Such screening of soil samples for cadaveric decomposition signature was successfully applied on two gravesoil sites and clearly differentiates soils at proximity of buried decaying pig carcasses from control soils.
\end{abstract}

(C) 2012 Elsevier B.V. All rights reserved.

\section{Introduction}

Forensic geotaphonomy is a branch of forensic anthropology focusing on the geological and botanical alteration of the surrounding environment of a buried dead body. The study of biochemical changes in soil related to the grave digging, to cadaver decomposition processes and to decomposition states themselves can be used in forensic investigation to estimate post-mortem interval and possibly locate clandestine graves or hidden remains of a victim. Despite this interest, the knowledge of the relation between cadaver decomposition and soil chemistry is still limited [1]. For

\footnotetext{
* Corresponding author at: University of Liège, CART, Biological and Organic Analytical Chemistry, Allée du 6 août, B6c, B-4000 Liège, Belgium. Tel.: +32 0436635 31; fax: +32043664387.

E-mail address: JF.Focant@ulg.ac.be (J.-F. Focant).
}

this reason, gravesoil is normally only used as associative evidence rather than as matrix that can potentially give information on cadaveric decomposition. It has been known for a long time that cadaver decomposition can influence gravesoil biology and chemistry [2]. Each stage of cadaver decomposition is known to have some specific effect on soil parameters (microbial activity, carbon dioxide production, $\mathrm{pH}$, electrical conductivity, etc.) $[3,4]$. During the various decay stages of a buried cadaver, a lot of different and specific volatile organic compounds (VOCs) are also emitted [5] and released into the soil. Some of those VOCs are responsible for the typical "smell of death" that we are able to sense, although some are only detected by sensitive organisms like scavenger insects or cadaver dogs [6-8]. Several groups are studying this specific VOC emission [9-14] but most of studies concern aboveground decomposition. Additionally, despite recent advances in VOC characterization and the establishment of a decomposition odor analysis database [9], there is still a lot of work to do to better characterize the olfactive signature of a decaying body. 
Such a characterization is essential to better understand mechanisms responsible for insect attraction and possibly be valuable for forensic entomology [15].

Analyzing mammalian decomposition products is an analytical challenge as complex reactions take place, resulting in the chemical breakdown of the body's main constituents (lipids, proteins and carbohydrates) [16]. For the analysis of VOCs produced during decomposition processes, gas chromatography (GC) coupled to mass spectrometry (MS) is the tool of choice. Solid-phase extraction (SPE) [17], solid-phase micro extraction (SPME) [9], thermal desorption (TD) [11-13,18] have been used for sample collection and transfer to GC-MS. A large range of volatile and semivolatile low to medium polar compounds can easily be analyzed by GC-MS, although polar analytes require a derivatization step prior analysis. Because of the large number of VOCs present in the chemical profile of decomposition odor [10], GC however easily suffers from peak capacity limitations. The use of non-scanning time-of-flight (TOF) MS analyzers that offer constant ion ratio over GC peaks can resolve some of the GC co-elutions in the MS domain by spectral deconvolution. However, such analytical resolution might suffer in efficiency as many compounds are issued from the same chemical families and are therefore characterized by similar mass spectral data, which complicates the deconvolution of the MS signal. Such a complex situation is further complicated in the case of gravesoil analysis as the soil matrix itself is made of various groups of chemical components, organisms, and debris [19].

Comprehensive two-dimensional gas chromatography $(\mathrm{GC} \times \mathrm{GC})$ has been developed to meet an increasing need for complex sample analysis and to address limitations such as peak capacity, dynamic range and restricted specificity of onedimensional (conventional) GC systems (1D-GC) (i.e. to improve the efficiency of the separation). GC $\times$ GC can be defined as a chromatographic technique during which a sample is subjected to two different separation processes coupled on-line [20]. In practice, the end of the first dimension $\left({ }^{1} \mathrm{D}\right)$ column is placed in a temperature controlled interface called 'the modulator' and further serially connected to the second dimension $\left({ }^{2} \mathrm{D}\right)$ column. The cryogenic modulator ensures high sampling rates and transfer of the sample to ${ }^{2} \mathrm{D}$ column [21]. Modulation also acts as a signal enhancer by zone compression [22]. The entire ${ }^{1} \mathrm{D}$ chromatogram is thus 'sliced' following a modulation period $\left(P_{\mathrm{M}}\right)$ of a few seconds and sent into ${ }^{2} \mathrm{D}$ for a fast GC-type separation [23]. By fine tuning of the GC phase combination, compounds potentially still co-eluting at the end of the ${ }^{1} \mathrm{D}$ can be separated on the basis of their different behaviors as regard of the ${ }^{2} \mathrm{D}$ phase. The separation power is increased and the sensitivity is enhanced [24]. For the detector responsible for recording the signal, everything happens as in classical GC and a trace is monitored continuously. In practice, series of high speed secondary chromatograms of a length equal to $P_{\mathrm{M}}(3-10 \mathrm{~s})$ are recorded one after another. They consist of slices that can be combined to describe the elution pattern by means of contour plots in the chromatographic separation space [25]. A software is responsible for processing the collected raw data and extract the multi-dimensional information. A complete description of GC $\times$ GC instrumental setup is available in a previous report [26]. GC $\times \mathrm{GC}$, often coupled to fast acquisition TOFMS, has thus been used to analyze complex samples in various fields, including VOC analyses [27-29].

To the best of our knowledge, despite the complexity of samples, GC $\times$ GC-TOFMS has never been used in the geoforensic field. Here, we report preliminary results on using GC $\times$ GC-TOFMS for the study of VOCs released in soil by buried decaying pig carcasses. The use of both retention times from the first dimension column, ${ }^{1} t_{\mathrm{R}}$, and from the second dimension column, ${ }^{2} t_{\mathrm{R}}$, peak intensity, deconvoluted mass spectral data as well as classification, scripting and simple chemometrics are combined to try to extract specific information about the composition and potential variations of the VOC mixture.

\section{Experimental}

\subsection{Field site}

The study site was a forest biotope, located in Belgium (Lambertcoordinates: 172800.00/167150.00). The field site was a research facility area devoted to forensic research managed by the Disaster Victim Identification (DVI) of the Belgian Federal Police. The tree layer of the field site was dominated by oak trees (Ouercus rubra, Quercus robur) and beech trees (Fagus sylvatica). The shrub layer was absent. The soil vegetation was scattered and the herb layer was mainly constituted by bracken (Pteridium aquilinum), blackberry (Rubus fructicosus), lily-of-the-Valley (Convallaria maialis) and May Lily (Maianthemum bifolium) during spring and summer. Concerning the moss layer, there were some spare spots of Polytrichum sp. The Belgian soil map indicated a dry sandy loam with strong drainage. The soil profile consisted of a humus topsoil A-horizon ( $\mathrm{pH} 2.1$ ), which overlaid a subsoil B-horizon $(\mathrm{pH}$ 3.9), with clear eluviation and illuviation layers. The environmental parameters were monitored using two data recording methods, semi-local weather data and microclimate data. Semi-local weather data (atmospheric temperatures and precipitations) were obtained from the nearest weather station (at $6.5 \mathrm{~km}$ of the experimental site) of the Royal Meteorological Institute of Belgium (KMI-IRM). Microclimate data were recorded using a tinytag dual channel temperature logger (TGP1520 ${ }^{\circledR}$, Gemini Dataloggers, Chichester, UK). One probe was used to measure temperature variations in the core (anus) of the pig's body and the other probe was placed $5 \mathrm{~cm}$ beneath the ground surface of the grave fill.

\subsection{Animal model}

Two pig (Sus domesticus L.) carcasses were used to model the human decomposition process [30-33]. Both carcasses were obtained within 10 days of death. In February 2008, the pig carcasses were buried in shallow graves dug by hand, at a depth of $40 \mathrm{~cm}$ and on their left side (as part of another cadaver decomposition forensic study [34]). The pig graves were backfilled within $3.5 \mathrm{~h}$ with the excavated soil in random fashion and compacted by gentle trampling. The same was performed with a single control pit used for comparison with both carcasses. The spacing between the graves was just over $1 \mathrm{~m}$. To avoid any vertebrate scavenging, a metal fence was placed around the grave site. After six months of burial, the graves were excavated by hand (at the beginning of August 2008) by a forensic investigation team (Fig. 1).

\subsection{Sampling procedure and collection of VOCs}

After six months of burial, gravesoil samples and control pit samples ( $300 \mathrm{~g}$ of soil) were collected at different depths during the pig excavation. Soil samples were taken at $5 \mathrm{~cm}, 10 \mathrm{~cm}, 20 \mathrm{~cm}$, $30 \mathrm{~cm}$ (sample above carcass) and $40 \mathrm{~cm}$ (sample below carcass) from both the pig graves and control pit for blank collection. Soil samples were hermetically packed in zip lock plastic bags, transferred to the laboratory and conserved at $-80^{\circ} \mathrm{C}$ until collection of the volatile fraction was carried out in laboratory conditions $\left(21^{\circ} \mathrm{C}\right)$. The size of sampling bags was selected to minimize the headspace. A dynamic sampling was used to collect VOCs released by gravesoil samples placed inside a closed volatile collection device (Fig. 2). The device was made of a pump (MSA, Escort Elf pump) pulling air through the sampling device at a constant rate of $0.5 \mathrm{~L} / \mathrm{min}$ for 1 or $2 \mathrm{~h}$ after $15 \mathrm{~min}$ of equilibration time. Gravesoil samples ( $50 \mathrm{~g}$ ) 

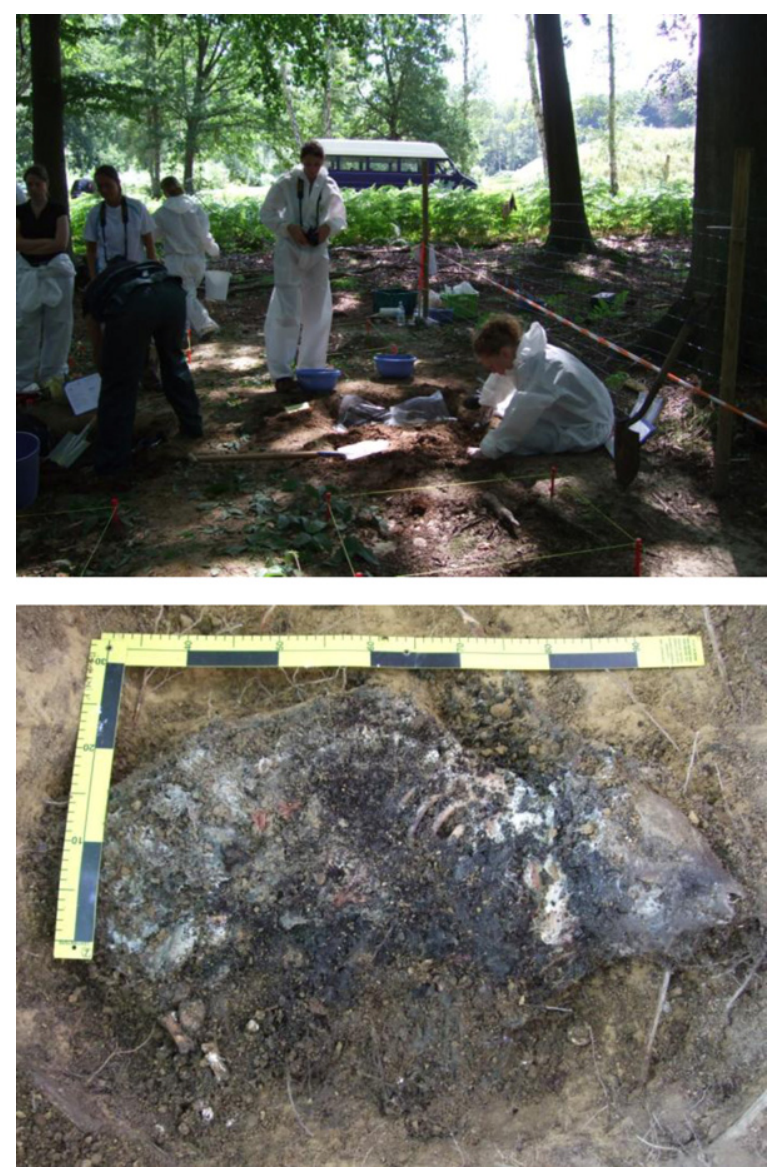

Fig. 1. The forensic excavation team removing layers of soil (top), and one of the pig carcasses after six months of burial at $40 \mathrm{~cm}$ depth (bottom).

were placed in a closed glass container $(250 \mathrm{~mL})$. It was connected to the trapping system by mean of glass and Teflon ${ }^{\circledR}$ tubing. VOCs were trapped on a cartridge containing a $60 \mu \mathrm{g}$ SuperQ ${ }^{\circledR}$ adsorbent filter (80-100 mesh, Alltech Associates, Inc., Deerfield, IL, USA). After sampling, VOCs were eluted from the SuperQ ${ }^{\circledR}$ adsorbent with $200 \mu \mathrm{L}$ of diethyl ether (HPLC grade, Sigma-Aldrich SA, Bornem, Belgium) and capped in GC-type vials prior GC-MS injection. The air pulled inside the sampling device was filtered through a carbon filter. An extra $60 \mu \mathrm{g}$ SuperQ ${ }^{\circledR}$ adsorbent filter was placed between the carbon filter and the sample to further avoid sample contamination and be used as blank.

\subsection{GC $\times$ GC-TOFMS analyses}

Samples were analyzed with the LECO GC $\times$ GC-TOFMS Pegasus 4D system (LECO corp., St Joseph, MI, USA) equipped with a $100 \%$ dimethylpolysiloxane $30 \mathrm{~m} \times 0.25 \mathrm{~mm} \times 0.25 \mu \mathrm{m}$ VF- $1 \mathrm{~ms}$

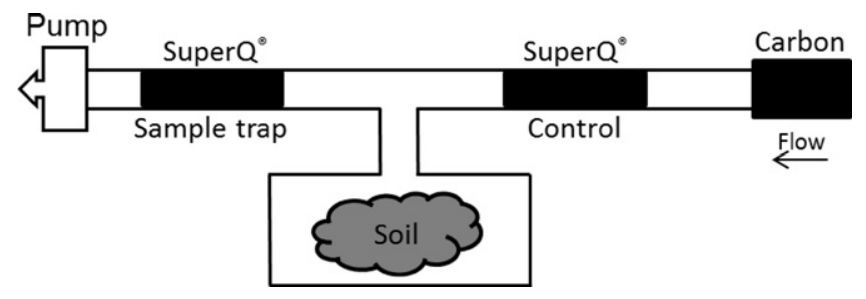

Fig. 2. Schematic diagram of the VOC dynamic sampling from soil samples. Air was pumped at a constant rate of $0.5 \mathrm{~L} / \mathrm{min}$ for 1 or $2 \mathrm{~h}$ after $15 \mathrm{~min}$ of equilibration time. The device was homemade and kept to its simplest design (a sample vial, a pump, glass and Teflon ${ }^{\circledR}$ tubing, and removable cartridges). phase as ${ }^{1} \mathrm{D}$ column and a 50\% phenyl, 50\% dimethylpolysiloxane $1 \mathrm{~m} \times 0.20 \mathrm{~mm} \times 0.10 \mu \mathrm{m}$ VF-17ms as ${ }^{2} \mathrm{D}$ column (Agilent, Waldbronn, Germany). Helium was used as the carrier gas at a constant flow rate of $1 \mathrm{~mL} / \mathrm{min}$. Two microliters of the sample in diethyl ether were injected into a split/splitless injector held at $270^{\circ} \mathrm{C}$ in splitless mode. The primary GC oven ramp temperature was programmed from $40^{\circ} \mathrm{C}$ to $220^{\circ} \mathrm{C}$ with a rate of $1.5^{\circ} \mathrm{C} / \mathrm{min}$. The secondary GC oven was set with an iso-ramping temperature mode and an offset temperature of $20^{\circ} \mathrm{C}$. The modulator system was a quad-jet with two permanent cold nitrogen jets and two pulsed hot-air jets. Liquid nitrogen was used to create the cold jets. The temperature offset of the modulator was $30^{\circ} \mathrm{C}$ with a $P_{\mathrm{M}}$ of $10 \mathrm{~s}$ and a hot pulse duration of $600 \mathrm{~ms}$. The MS transfer line temperature was $250^{\circ} \mathrm{C}$. The ion source temperature was $200^{\circ} \mathrm{C}$ with EI energy of $70 \mathrm{eV}$. The collected mass range was $20-600 \mathrm{amu}$ with an acquisition rate of 100 spectra/s and detector voltage of $1800 \mathrm{~V}$. The data were processed with the LECO ChromaTOF 4.22 automated peak find and spectral deconvolution software with a defined signalto-noise threshold. Wiley (2008) and NIST (2008) mass spectral libraries were used for temptative identification. An alkane standard $\left(C_{8}-C_{20}\right)$ solution was run for the calculation of retention indices, based on the following formula.

${ }^{1} \mathrm{DRI}$ (target) $=100\left(\frac{{ }^{1} t_{\mathrm{R}}(s)-{ }^{1} t_{\mathrm{R}}(n)}{{ }^{1} t_{\mathrm{R}}(n+1)-{ }^{1} t_{\mathrm{R}}(n)}+n\right)$

For data analyses, the comparison algorithm available in the ChromaTOF 4.22 software was used. Reference peak tables were created by processing of the gravesoil samples of all depths, based on minimum signal to noise ratio $(\mathrm{S} / \mathrm{N})$ and specified library matches as minimum requirements for a peak to be included in peak tables. Further classification processes were applied to remove the chromatographic noise (column bleed) and potential peak tailing issues. Each control samples were processed against the reference tables to identify non decomposition specific compounds and remove them from the list of candidate specific analytes. Further comparisons were realized between the lists of candidate specific analytes to potentially identify differences in the VOC content of soils taken at different depths. Comparisons were based on deconvoluted peak retention time $\left({ }^{1} t_{R}\right.$ and $\left.{ }^{2} t_{R}\right)$, apex mass spectra and relative area. A retention reference compound was used to account for potential retention time shifts due to GC column related factors. Retention time variations of $20 \mathrm{~s}$ (twice $P_{\mathrm{M}}$ ) and $0.2 \mathrm{~s}$ were set for ${ }^{1} \mathrm{D}$ and ${ }^{2} \mathrm{D}$, respectively. To help in the non-target analytical approach, the classification of the chromatographic peaks was also based on recognizable feature in the mass fragmentation pattern $[35,36]$. This approach is possible by creating and applying scripts to evaluate the mass spectral data for these characteristic mass spectral features. Scripts were written in Microsoft ${ }^{\mathrm{TM}}$ VBScript language, set in different functions and incorporated in classification procedures of the ChromaTOF 4.22 software. Chromatographic peaks matching the mass spectral pattern of compounds of interest were labeled and therefore highlighted among the large quantity of peaks found in each sample. The application of scripts reduced the number of compounds for manual review and allowed to confirm the specificity of some compounds found in our gravesoil samples.

\subsection{Statistical analyses}

Multivariate analysis was performed on data using principal component analysis (PCA) (The Unscrambler ${ }^{\circledR}, \mathrm{v}$ 10.0). PCA is a projection method used to get a better overview and a visual representation of relationships between samples and variables. The information from initial variables is combined and reduced generally to a bi- or tri-dimensional system represented with the 


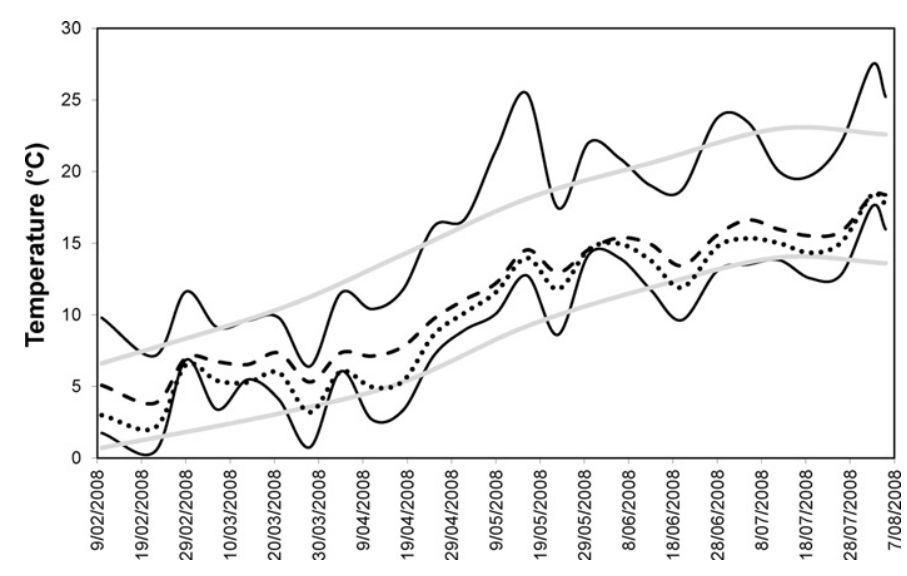

Fig. 3. Comparison between minimum and maximum average air temperatures in Belgium during the study period and temperatures recorded at the experimental site for air, at subsurface, and at carcass level. (gray lines) KMI-IRM archives minimum-maximum air $T$ during the study, (black lines) average recorded minimum-maximum air $T$ for the study area, (black dots) subsurface recorded $T$ during the study, (black dashes) pig core recorded $T$ during the study.

principal components (PCs) and taking in account the most important information. In this study, the matrix was set with the pig gravesoil samples as objects and the VOCs (using chromatogram area values) as variables in order to show a potential structure within the data and through depth. The Student's $t$-distribution statistical hypothesis test was used to show significant differences between pig grave and control samples obtained with the script filtering method.

\section{Results and discussion}

\subsection{Environmental parameters}

Pig graves and the control pit were located close to each other $(1 \mathrm{~m})$ to reduce the soil composition variability. Shorter distance would potentially have been problematic in terms of cross leaching of decomposition products. The forest biotope of the study is representative of typical Belgian forest. The 6 months period of burial ranged from February to August 2008. Local atmospheric temperature and precipitation values were close to seasonal averages. Mean precipitations over the 6 months study period were $62.9 \mathrm{~mm} /$ month. Mean precipitations from the Belgian KMI-IRM archives for the same 6 months over the range 1981-2010 was $66.0 \mathrm{~mm} / \mathrm{month}$ (4.7\% deviation). The maximum and minimum air temperature values were recorded daily and the calculated monthly averages (range of $3.0-22.2{ }^{\circ} \mathrm{C}$ ) were close to average temperatures reported for the last 20 years (range of $0.7-23.0^{\circ} \mathrm{C}$ ) with $2-3{ }^{\circ} \mathrm{C}$ higher for February and May (Fig. 3). Lower temperature variations were observed for subsurface and carcass. Subsurface temperature range was $3.9-15.5^{\circ} \mathrm{C}$, and the carcass temperature range was $5.3-16.3^{\circ} \mathrm{C}$ (Fig. 3). These environmental parameters can therefore be considered as typical for the geographical area. Additional detailed information on soil parameters is available elsewhere [34].

\subsection{Data treatment strategy to select candidate specific analytes}

For the establishment of a list of candidate specific analytes, the complete samples set of one of the pig graves (pig A) was investigated and compared to the control pit samples. The gravesoil samples were processed with a S/N threshold value of 200 in order to limit the number of hits to the most significant compounds. For further refinement of the list, a library match value of 700 was applied and chromatographic noise and peak tailing were removed from the hit table. This approach conducted to the selection of a limited number of analytes per sample (Table 1 ). A reference table was built for each separate gravesoil sample at different depths and every single control pit soil samples, also taken at different depths, were processed versus those reference tables. According to the library search, hydroxybutylated toluene was found in every sample at significant level and was used as retention reference compound for retention time adjustment in both ${ }^{1} \mathrm{D}$ and ${ }^{2} \mathrm{D}$. In practice, compounds that were not found in any of the control pit soil samples or with an area value lower than $10 \%$, relatively to the same analyte found in the carcass sample were kept as candidate specific analytes. Compounds that were found in at least one of the different depths control pit soil samples were rejected from the list of candidates. A list of specific compounds was established for each depth of the pig grave (Table 1 ). The highest numbers of compounds were found in samples taken at the surface (depth $5 \mathrm{~cm}, n=31$ ) and below the carcass $(n=30)$. Amongst all samples, several compounds were observed in multiple layers of soils.

\subsection{Differentiation between two groups of compounds}

In order to highlight possible differences between the various depths of gravesoils, based on the candidate specific analytes reported in Table 1, all gravesoil samples were reprocessed with a threshold $\mathrm{S} / \mathrm{N}$ value of 5 to check if some compounds of a specific depth were present in the other depth samples at a lower $\mathrm{S} / \mathrm{N}$ than 200 , potentially improving the specificity. All reprocessed reference table were cross compared to determine what were the depthspecific and recurrent analytes. It appeared that a large majority of analytes were present at every depth of the pig grave, except for some compounds that showed to be specific to the sample taken below the pig carcass.

Practically, 20 specific compounds were specifically found in the soil sample taken below the carcass (Table 2 ). The identity of the compounds resulted from the library searching based on mass spectral data and from further comparison of ${ }^{1} \mathrm{D}$ retention indices $\left({ }^{1} \mathrm{DRI}\right)$ values calculated against reference alkanes and values available in the literature. Additional structural analysis investigation of the fragmentation pattern completed the identification process when more than one candidate was possible. This group of 20 compounds consisted of ketones $(n=7)$, nitriles and sulfurs $(n=4)$, heterocyclic compounds $(n=3)$, and benzene derivatives like aldehydes, alcohols, ketones, ethers and nitriles $(n=6)$. Some of these compounds were already reported in the literature (see Table 2 ). Some others were not but could be linked to typical degradation products issued from soft tissues [11]. Surprisingly, several families of compounds, such as acids, esters, aldehydes and alcohols, usually detected when monitoring decomposition processes were not identified. As other typical amino acids or bone fat microorganisms metabolization products were detected (indole, phenol, benzaldehyde, benzonitrile, acetophenone, dimethyldisulfide, dimethyltrisulfide, and 2-nonanone [5]), and as the body did clearly undergo all decomposition stages up to skeletonization (Fig. 1), the absence of these specific VOCs was most probably to be related to either the analytical sampling procedure or the removal of the soil signature during data processing. The liquid extraction of the analytes from the sampling cartridges as well as the storage of the liquid fraction prior analyses is not adequate for the most volatile polar compounds, compared to the use of direct thermal desorption to the GC column.

On the other hand, the dynamic VOC collection and concentration before liquid extraction could also be responsible of the detection of a second group of candidate specific compounds. That group consisted of 34 compounds found at all depths of the gravesoil samples. This group included alkane isomers ranging from $\mathrm{C}_{12}$ to $\mathrm{C}_{16}$, made of methyl-branched alkanes including methyl-, dimethyl-, trimethyl-, tetramethyl-, and heptamethyl-isomers. The 
Table 1

Summary of the data processing results for the determination of candidate specific compounds for the various layers of gravesoil (pig A).

\begin{tabular}{|c|c|c|c|}
\hline \multirow[t]{2}{*}{ Gravesoil samples } & \multicolumn{3}{|l|}{ Automated peak finding } \\
\hline & $\begin{array}{l}\text { With S/N threshold at } \\
200 \text { (a) }\end{array}$ & $\begin{array}{l}\text { With (a) and library match }>700 \\
\text { bleed and tailing removed (b) }\end{array}$ & $\begin{array}{l}\text { With (a) and (b) and cleaned from } \\
\text { analytes present in controls }\end{array}$ \\
\hline Depth $5 \mathrm{~cm}$ & 545 & 170 & 31 \\
\hline Depth $10 \mathrm{~cm}$ & 519 & 129 & 17 \\
\hline Depth $20 \mathrm{~cm}$ & 401 & 103 & 9 \\
\hline Above carcass & 442 & 108 & 10 \\
\hline Below carcass & 611 & 153 & 30 \\
\hline
\end{tabular}

exact identification of these compounds was difficult because of the complexity of the MS fragmentation patterns. This not only prevented the clear localization of the methyl groups on the alkane chains, but also significantly reduced the efficiency of the library searching. Even the use of ${ }^{1}$ DRI calculation was not conducive to unique identifications. Very good library matches were questioned by ${ }^{1}$ DRI values that highlighted discrepancies between the proposed number of carbon atoms and the predicted position in the chromatographic space.

These methyl-branched alkanes were nevertheless specific to the gravesoil samples. Only a few reports mention the detection of these compounds, especially when using a similar dynamic collection technique based on an extended time of accumulation, potentially leading to enrichment in these volatiles [11,12,14]. Furthermore, the use of the sensitive GC $\times$ GC-TOFMS instrument and both the associated enhanced peak capacity and spectral deconvolution also contributed to highlight the presence of the specific alkane fraction. Fig. 4 shows the apex plot for the 54 compounds of interest and the alkane retention standard mixture. The segregation between the two groups of analytes over the chromatographic retention area is significant with a characteristic elution band at short ${ }^{2} t_{\mathrm{R}}$ for methyl-branched alkanes, and a larger dispersion in the chromatographic space for the more functionalized compounds.

The emission of methyl-branched alkanes has been reported in studies in relation with specific oxidative stresses [40,41]. The hypothesis was that volatile methyl-branched alkanes were produced by the lipid peroxidation of polyunsaturated fatty acids of cell membranes, itself initiated by reactive oxygen species (ROS) issued from oxidative stresses. Such a mechanism could logically occur in decaying carcasses as it is well known that the production

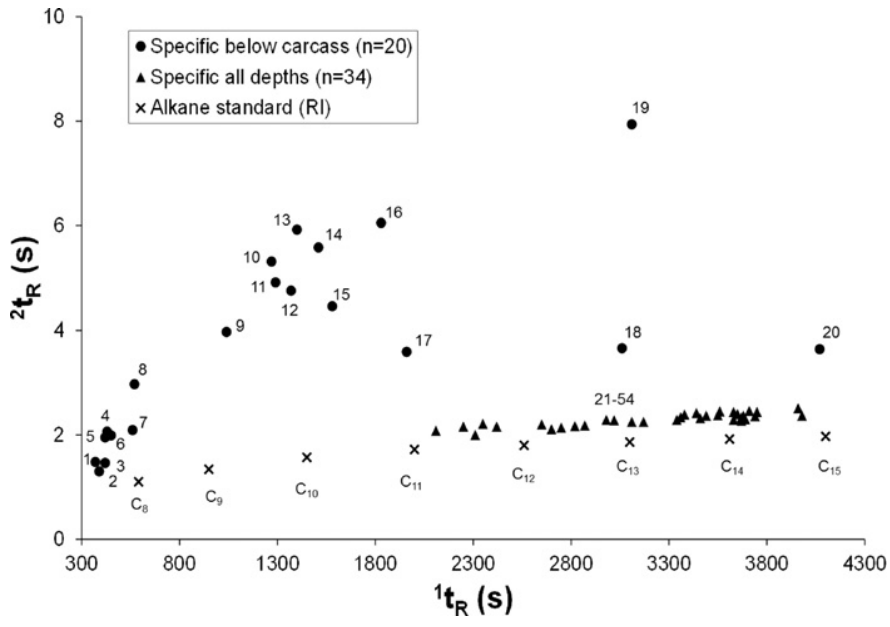

Fig. 4. Apex plot showing the spatial distribution of the two groups of specific analytes. The numbering system refers to Table 2 .

of ROS is increased after death when antioxidant defense mechanisms end [5]. Another source of methyl-branched alkanes to also consider would be related to ants, as these analytes are known to be one of the main constituent of the ant cuticular hydrocarbon mixture used in signal discrimination [42], and have been already investigated to Forensic applications [43]. Despite the facts that very low concentrations are to be expected and that longer carbon chain compounds are reported, the contribution of these cuticle hydrocarbons to the VOCs pattern is possible and already earlier suggested [5].

Table 2

List of the specific compounds identified in the gravesoil sample below the carcass $\left({ }^{1} t_{\mathrm{R}}\right.$ and ${ }^{2} t_{\mathrm{R}}$ for first and second dimension retention times, respectively).

\begin{tabular}{|c|c|c|c|c|c|}
\hline \multicolumn{2}{|c|}{ Compounds } & \multicolumn{2}{|c|}{ Retention times (s) } & \multirow[t]{2}{*}{ Molecular formula } & \multirow[t]{2}{*}{ Literature report } \\
\hline Number & Identity & ${ }^{1} t_{\mathrm{R}}$ & ${ }^{2} t_{\mathrm{R}}$ & & \\
\hline 1 & Pentane-2,3-dione & 370 & 1.48 & $\mathrm{C}_{5} \mathrm{H}_{8} \mathrm{O}_{2}$ & \\
\hline 2 & Tetrahydro-2,5-dimethylfuran & 390 & 1.30 & $\mathrm{C}_{6} \mathrm{H}_{12} \mathrm{O}$ & \\
\hline 3 & 2,2,4-Trimethyloxetane & 420 & 1.46 & $\mathrm{C}_{6} \mathrm{H}_{12} \mathrm{O}$ & \\
\hline 4 & 2-Methylbutanenitrile & 420 & 1.95 & $\mathrm{C}_{5} \mathrm{H}_{9} \mathrm{~N}$ & \\
\hline 5 & 3-Methylbutanenitrile & 430 & 2.06 & $\mathrm{C}_{5} \mathrm{H}_{9} \mathrm{~N}$ & \\
\hline 6 & Dimethyldisulfide & 450 & 1.99 & $\mathrm{C}_{2} \mathrm{H}_{6} \mathrm{~S}_{2}$ & {$[9-14,32,38,39]$} \\
\hline 7 & Hexane-2,3-dione & 560 & 2.09 & $\mathrm{C}_{6} \mathrm{H}_{10} \mathrm{O}_{2}$ & \\
\hline 8 & Cyclopentanone & 570 & 2.97 & $\mathrm{C}_{5} \mathrm{H}_{8} \mathrm{O}$ & \\
\hline 9 & Methoxybenzene & 1040 & 3.97 & $\mathrm{C}_{7} \mathrm{H}_{8} \mathrm{O}$ & \\
\hline 10 & Benzaldehyde & 1270 & 5.31 & $\mathrm{C}_{7} \mathrm{H}_{6} \mathrm{O}$ & {$[9,13,14,38]$} \\
\hline 11 & Dimethyltrisulfide & 1290 & 4.91 & $\mathrm{C}_{2} \mathrm{H}_{6} \mathrm{~S}_{3}$ & {$[9-12,14,32,39]$} \\
\hline 12 & Phenol & 1370 & 4.75 & $\mathrm{C}_{6} \mathrm{H}_{6} \mathrm{O}$ & {$[10,12,14]$} \\
\hline 13 & Benzonitrile & 1400 & 5.92 & $\mathrm{C}_{7} \mathrm{H}_{5} \mathrm{~N}$ & {$[9,14]$} \\
\hline 14 & Cyclohept-4-en-1-one & 1510 & 5.58 & $\mathrm{C}_{7} \mathrm{H}_{10} \mathrm{O}$ & \\
\hline 15 & 1-Methoxy-4-methylbenzene & 1580 & 4.45 & $\mathrm{C}_{8} \mathrm{H}_{10} \mathrm{O}$ & \\
\hline 16 & Acetophenone & 1830 & 6.05 & $\mathrm{C}_{8} \mathrm{H}_{8} \mathrm{O}$ & {$[12,14]$} \\
\hline 17 & Nonan-2-one & 1960 & 3.59 & $\mathrm{C}_{9} \mathrm{H}_{18} \mathrm{O}$ & {$[10,12,14,37]$} \\
\hline 18 & Undecan-2-one & 3060 & 3.66 & $\mathrm{C}_{11} \mathrm{H}_{22} \mathrm{O}$ & \\
\hline 19 & Indole & 3110 & 7.94 & $\mathrm{C}_{8} \mathrm{H}_{7} \mathrm{~N}$ & {$[13,14,18,32,38]$} \\
\hline 20 & Tridecan-2-one & 4070 & 3.64 & $\mathrm{C}_{13} \mathrm{H}_{26} \mathrm{O}$ & \\
\hline
\end{tabular}




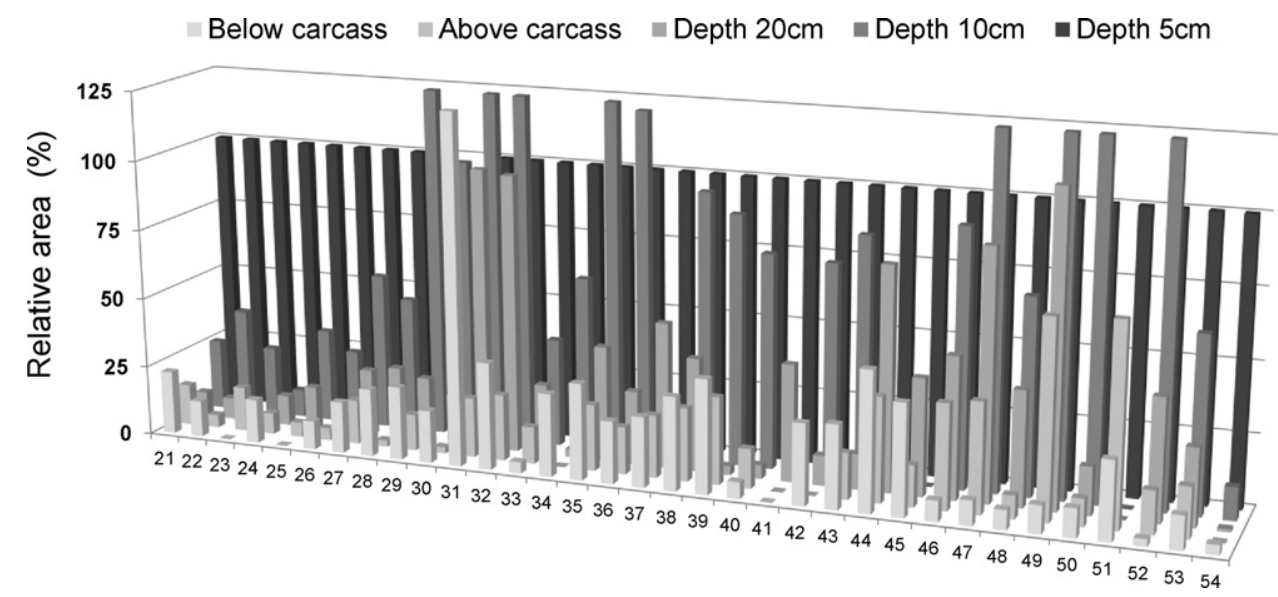

Fig. 5. Variation in levels of specific methyl-branched alkanes $\left(C_{12}-C_{16}\right)$ with the distance from the decaying carcass. Numbers refer to the 34 analytes.

\subsection{Apparent depth trend in soil}

In addition to the separation between the group of functionalized molecules $(n=20)$ present below the carcass and the methyl-branched alkane group $(n=34)$, a trend in the relative presence of these alkanes over the various layers of soils was observed.

A main reason for the presence of the specific compounds below the carcass is the leaching and percolation of degradation fluids by gravity. These compounds can later barely migrate upwards to the surface of the soil as they are shielded by the carcass itself. Additionally, considering that the adsorption of VOCs on soil particles increases with the polarity of the compounds, mainly based on ion-dipole interactions and $\pi$ electrons donations, different behaviors were to be expected between functionalized and alkane molecules [44]. Aliphatic low polar compounds could thus undergo weaker soil adsorption with interactions of London-van der Waals force type (induced dipole-induced dipole), possibly resulting in higher migration rate. Such an effect would even be more significant for methyl-branched alkanes as they are characterized by lower van der Waals forces. This is currently only hypothesis that still have to be verified. Furthermore, as humidity influences the adsorption of compounds onto soil due to competition with soil interaction with water molecules [44], the water content of the soil would additionally weaken possible interaction between soil and aliphatic compounds.

Concerning the distribution of the methyl-branched alkanes between the different layers of soils, after normalization of the relative area of each of the 34 compounds found at all depths, to the area values of the compounds in the surface sample (depth $5 \mathrm{~cm}$ ), some concentration trends appeared. As illustrated in Fig. 5, an increase in the amount of the specific alkanes is highlighted when coming from the carcass to the surface. It was difficult to relate this observation with other reports. An external contamination of the soil by oil or any other possible source of branched alkanes is unlikely as control samples were subtracted to gravesoil samples. Furthermore, such depth trend was not observed for other non-specific alkanes in control soils.

PCA analyses identified a similar trend, highlighting the distribution of the gravesoil samples taken at different depths in a score plot, obtained after loading the area values of the similar methyl-branched alkanes as variables in the matrix. The soil samples closer to the carcass (below carcass, above carcass and at a depth of $20 \mathrm{~cm}$ ) expressed similar spatial distribution although samples taken closer to the surface (depths of $5 \mathrm{~cm}$ and $10 \mathrm{~cm}$ ) were clustered together (Fig. 6). The first component (PC-1, 93\%) covered most of the information and showed the separation of the $5 \mathrm{~cm}$ and $10 \mathrm{~cm}$ depths from the others.

\subsection{Utilization of scripts to screen for cadaveric decomposition signature in soil samples}

Following the idea of using GC $\times$ GC-TOFMS in forensic geotaphonomy for screening of soil samples for cadaveric decomposition signature, a procedure for filtering of peak tables generated from suspected soil using scripting was investigated. Based on recognizable features in the mass spectra of the methyl-branched alkanes found at high level in the upper layers of gravesoils, we wrote a script that includes the major spectral specificities (Fig. S1). Straight-chain alkanes spectra are characterized by $\mathrm{C}_{n} \mathrm{H}_{2 n+1}^{+}$and less abundant $\mathrm{C}_{n} \mathrm{H}_{2 n-1}{ }^{+}$charged fragments series, with maxima around $\mathrm{C}_{3}$ and $\mathrm{C}_{4}$. Branched-chain alkanes show a decrease in molecular ions and $\mathrm{C}_{n} \mathrm{H}_{2 n+1}{ }^{+}$along with $\mathrm{C}_{n} \mathrm{H}_{2 n}{ }^{+}$ion series increase through cleavage and charge retention at the branched carbon [45]. The samples set of the two pig graves (pig A and B) and control pit were tested with scripting. The second gravesoil experiment (pig B) was used to confirm the observation obtained from the pig A samples. To simplify the sampling process, the gravesoil samples of pig $B$ were tested with $1 \mathrm{~h}$ of extraction time (in comparison with $2 \mathrm{~h}$ for pig A). The control pit soil samples were also tested with $1 \mathrm{~h}$ of extraction time to include the influence of the extraction time on the results. The script was applied on raw peak tables generated by processing samples using different peak finding processes with S/N thresholds of 200, 50 and 10 . The various levels of S/N

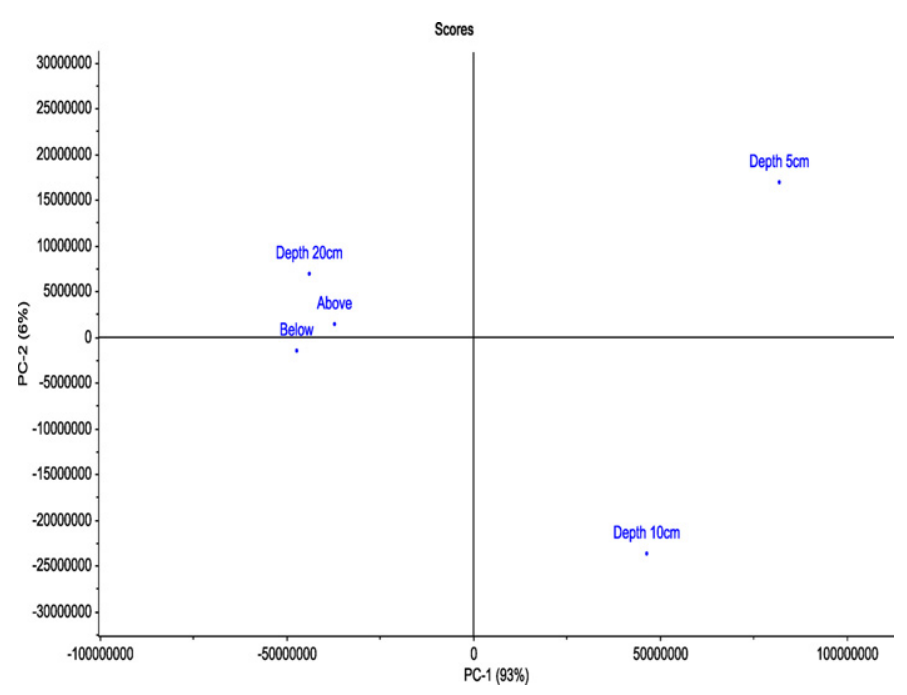

Fig. 6. PCA of the different layers of gravesoils based on relative area of specific methyl-branched alkanes. 


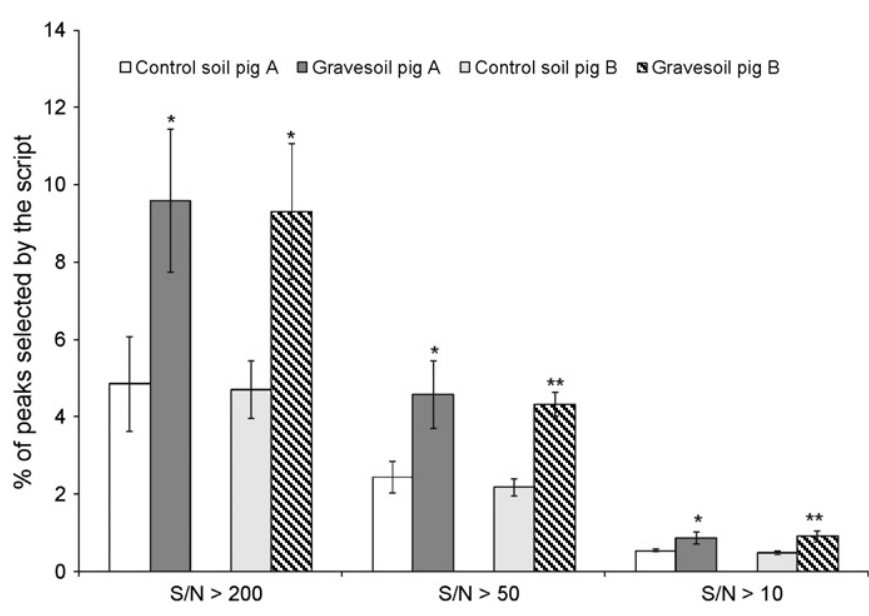

Fig. 7. Comparison of the percentage of peaks selected by applying the alkanespecific script to gravesoil and control samples processed at various $\mathrm{S} / \mathrm{N}$ values. Single and double stars represent Student's $t$-distribution test with $\rho$ value $<0.05$ and $\rho$ value $<0.01$, respectively.

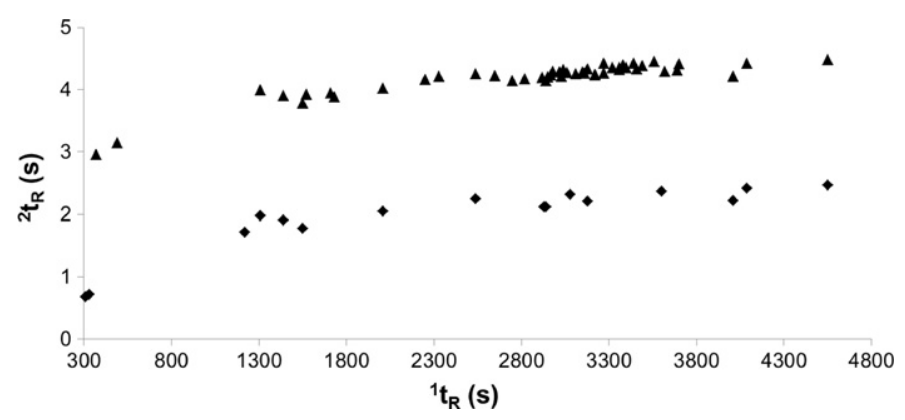

Fig. 8. Apex plot for both gravesoil (pig A) and control results after scripting of soils at $10 \mathrm{~cm}$ depth (S/N of 200). Diamonds are for control soil ( $n=16$ hits), and triangles are for gravesoil ( $n=47$ hits). Gravesoil ${ }^{2} t_{R}$ have been shifted of $2 \mathrm{~s}$ for clarity.

thresholds were investigated to find a compromise between peak table sizes and specificity. The major issue was the potential generation of very large peak tables requiring long and tedious data processing procedures. The average numbers of hits in the peak tables were 500, 2000 and 13,000 for S/N thresholds of 200, 50 and 10 , respectively. After compounds with the recognizable alkane or methyl-branched alkane fragmentation pattern were isolated by scripting through the peaks table, the numbers of hits were reduced to values between $0.5 \%$ and $10 \%$ of the initial numbers. Fig. 7 shows the mean percentage values for the number of hits obtained after the script was applied to peak tables generated at different $\mathrm{S} / \mathrm{N}$ threshold levels for the three upper layers of the soils (depths 5, 10 and $20 \mathrm{~cm}$ ) and for the two different gravesoil experiments (pig $A$ and B) and their respective control samples. The Student's $t$ distribution test showed significant differences ( $\rho$ value $<0.05$ or 0.01 ) between gravesoil samples and control samples for every $S / N$ threshold levels tested. A S/N of 200 appeared to be sufficient to highlight the difference between gravesoil and control samples. Fig. 8 illustrates the apex plot for both gravesoil pig A and control results after scripting of soils at $10 \mathrm{~cm}$ depth processed at $S / N$ of 200. The cadaveric decomposition signature is clearly highlighted by applying the script.

\section{Conclusions}

The analysis of gravesoil samples by GC $\times$ GC-TOFMS conducted to the identification of two main groups of specific analytes. A first group of 20 functionalized compounds specifically located below the carcass, and a second group of methyl-branched alkanes present in all gravesoil samples. A trend in the relative presence of these alkanes over the various layers of soils was observed. The use of a specific script permitted to propose a data treatment strategy to potentially screen for cadaveric decomposition signature in soil samples. This strategy could complement other approaches [46] and contribute to aid forensic geotaphonomy investigators.

\section{Acknowledgements}

J. Dekeirsschieter was the recepient of a PhD grant from F.R.I.A. (Fonds pour la Formation à la Recherche dans l'Industrie et l'Agriculture). Donald C. Hilton and Yves Brostaux are acknowledged for their help in writing in Microsoft ${ }^{\mathrm{TM}}$ VBScript language and statistical data treatment, respectively. The authors would also like to thank the Disaster Victim Identification team, the Air Support Unit and the National Technical and Tactical Support Unit of the Belgian Federal Police. Thanks to all individuals who helped with fieldwork, especially the students from the University of Applied Sciences (HvA) in Amsterdam.

\section{Appendix A. Supplementary data}

Supplementary data associated with this article can be found, in the online version, at doi:10.1016/j.chroma.2012.03.048.

\section{References}

[1] M. Tibbett, D.O. Carter, in: K. Ritz, L. Dawson, D. Miller (Eds.), Criminal and Environmental Soil Forensics, Springer, New York, 2009, p. 317.

[2] J.A. Payne, E.W. King, G. Beinhart, Nature 219 (1968) 1180.

[3] L.A. Benninger, D.O. Carter, S.L. Forbes, Forensic Sci. Int. 180 (2008) 70.

[4] K.L. Stokes, S.L. Forbes, L.A. Benninger, D.O. Carter, M. Tibbett, in: K. Ritz, L. Dawson, D. Miller (Eds.), Criminal and Environmental Soil Forensics, Springer, New York, 2009, p. 357.

[5] S. Paczkowski, S. Schütz, Appl. Microbiol. Biotechnol. 91 (2011) 917.

[6] G.S. Anderson, S.L. VanLaerhoven, J. Forensic Sci. 41 (1996) 617.

[7] D.T. Hudson, A.M. Curran, K.G. Furton, J. Forensic Sci. 54 (2009) 1270.

[8] A.M. Curran, P.A. Prada, K.G. Furton, J. Forensic Sci. 55 (2010) 50.

[9] A.A. Vass, R.R. Smith, C.V. Thompson, M.N. Burnett, D.A. Wolf, J.A. Synstelien, N. Dulgerian, B.A. Eckenrode, J. Forensic Sci. 49 (2004) 760.

[10] A.A. Vass, R.R. Smith, C.V.Thompson, M.N. Burnett, N. Dulgerian, B.A. Eckenrode, J. Forensic Sci. 53 (2008) 384.

[11] M. Statheropoulos, C. Spiliopoulou, A. Agapiou, Forensic Sci. Int. 153 (2005) 147.

[12] M. Statheropoulos, A. Agapiou, C. Spiliopoulou, G.C. Pallis, E. Sianos, Sci. Total Environ. 385 (2007) 221.

[13] E.M. Hoffman, A.M. Curran, N. Dulgerian, R.A. Stockham, B.A. Eckenrode, Forensic Sci. Int. 186 (2009) 6.

[14] J. Dekeirsschieter, F.J. Verheggen, M. Gohy, F. Hubrecht, L. Bourguignon, G. Lognay, E. Haubruge, Forensic Sci. Int. 189 (2009) 46.

[15] C. von Hoermann, J. Ruther, S. Reibe, B. Madea, M. Ayasse, Forensic Sci. Int. 212 (2011) 173.

[16] L.M. Swann, S.L. Forbes, S.W. Lewis, Anal. Chim. Acta 682 (2010) 9

[17] S.J. Notter, B.H. Stuart, B.B. Dent, J. Keegan, Eur. J. Lipid Sci. Technol. 110 (2008) 73.

[18] A.A. Vass, S.-A. Barshick, G. Sega, J. Caton, J.T. Skeen, J.C. Love, J.A. Synstelien, J. Forensic Sci. 47 (2002) 542.

[19] A.R. Conklin, Introduction to Soil Chemistry: Analysis and Instrumentation, Wiley, New Jersey, 2005.

[20] J.C. Giddings, Anal. Chem. 56 (1984) 1258A.

[21] E.B. Ledford, C.A. Billesbach, J. High Resolut. Chromatogr. 23 (2000) 202.

[22] D.G. Patterson Jr., S.M. Welch, W.E. Turner, A. Sjödin, J.-F. Focant, J. Chromatogr. A 1218 (2011) 3274.

[23] J.-F. Focant, E. Reiner, K. MacPherson, T. Kolic, A. Sjödin, D.G. Patterson Jr., S. Reese, F. Dorman, J. Cochran, Talanta 63 (2004) 1231.

[24] J.B. Phillips, J. Beens, J. Chromatogr. A 856 (1999) 331.

[25] J.-M.D. Dimandja, Anal. Chem. 76 (2004) 167A.

[26] G. Semard, M. Adahchour, J.-F. Focant, in: L. Ramos (Ed.), Comprehensive Two Dimensional Gas Chromatography in: D. Barcelo (Ed.), Wilson and Wilson's Comprehensive Analytical Chemistry, Elsevier, The Netherlands, 2009, p. 15.

[27] Z.L. Cardeal, P.P. de Souza, M.D.R. Gomes da Silva, P.J. Marriott, Talanta 74 (2008) 793.

[28] I. Silva, S.M. Rocha, M.A. Coimbra, P.J. Marriott, J. Chromatogr. A 1217 (2010) 5511.

[29] C. Cordero, E. Liberto, C. Bicchi, P. Rubiolo, P. Schieberle, S.E. Reichenbach, Q. Tao, J. Chromatogr. A 1217 (2010) 5848. 
[30] D.L. France, T.J. Griffin, J.G. Swanburg, J.W. Lindermann, G.C. Davenport, V. Trammell, J. Forensic Sci. 37 (1992) 1445.

[31] B. Turner, P. Wiltschire, Forensic Sci. Int. 101 (1999) 113.

[32] B.B. Dent, S.L. Forbes, B.H. Stuart, Environ. Geol. 45 (2004) 576.

[33] K.G. Schoenly, N.H. Haskell, D.K. Mills, C. Bieme-Ndi, K. Larsen, Y. Lee, Am. Biol. Teach. 68 (2006) 402.

[34] E.M.J. Schotsmans, J. Denton, J. Dekeirsschieter, T. Ivaneanu, S. Leentjes, R.C. Janaway, A.S. Wilson, Forensic Sci. Int. (2011), doi:10.1016/j.forsciint.2011.09.025.

[35] D.C. Hilton, Curr. Trends Mass Spectrom. (2007) 28.

[36] D.C. Hilton, R.S. Jones, A. Sjödin, J. Chromatogr. A 1217 (2010) 6851.

[37] D. Ercolini, F. Russo, A. Nasi, P. Ferranti, F. Villani, Appl. Environ. Microb. 75 (2009) 1990.

[38] N. Lorenzo, T. Wan, R. Harper, Y. Hsu, M. Chow, S. Rose, K. Furton, Anal. Bioanal. Chem. 376 (2003) 1212
[39] B. Kalinova, H. Podskalska, J. Ruzicka, M. Hoskovec, Naturwissenschaften 96 (2009) 889.

[40] M. Phillips, K. Gleeson, J.M.B. Hughes, J. Greenberg, R.N. Cataneo, L. Bager, W.P. McVay, Lancet 353 (1999) 1930.

[41] M. Phillips, R.N. Cataneo, J. Greenberg, R. Gunawardena, A. Naidu, F. Rahbari-Oskoui, J. Lab. Clin. Med. 136 (2000) 243.

[42] S. Martin, F. Drijfhout, J. Chem. Ecol. 35 (2009) 1151.

[43] G.H. Zhu, X.H. Xu, X.J. Yu, Y. Zhang, J.F. Wang, Forensic Sci. Int. 169 (2007) 1.

[44] J. Ruiz, R. Bilbao, M.B. Murillo, Environ. Sci. Technol. 32 (1998) 1079.

[45] F.W. McLafferty, F. Turecek, Interpretation of Mass Spectra, 4th ed., University Science Books, California, 1993.

[46] T.M. Lovestead, T.J. Bruno, Forensic Sci. Int. 204 (2011) 156. 